\title{
Cost effectiveness and cost utility of an organized screening programme for glaucoma
}

\author{
Hanna Vaahtoranta-Lehtonen, ${ }^{1}$ Anja Tuulonen, ${ }^{2}$ Pasi Aronen, ${ }^{3,4}$ \\ Harri Sintonen, ${ }^{3,4}$ Liisa Suoranta, ${ }^{5}$ Niina Kovanen, ${ }^{3}$ Miika \\ Linna, ${ }^{6}$ Esa Läärä ${ }^{7}$ and Antti Malmivaara ${ }^{3}$ \\ ${ }^{1}$ Department of Ophthalmology, Turku City Hospital, Turku, Finland \\ ${ }^{2}$ Department of Ophthalmology, University of Oulu, Oulu, Finland \\ ${ }^{3}$ Finnish Office for Health Technology Assessment (FinOHTA), Helsinki, Finland \\ ${ }^{4}$ Department of Public Health, University of Helsinki, Finland \\ ${ }^{5}$ Hospital Mehiläinen, Helsinki, Finland \\ ${ }^{6}$ The Centre for Health Economics at Stakes (CHESS), Helsinki, Finland \\ ${ }^{7}$ Department of Mathematical Sciences, University of Oulu, Oulu, Finland
}

\begin{abstract}
.
Purpose: To assess the cost effectiveness and cost utility of an organized screening programme for glaucoma. The previous cost-effectiveness studies of screening show inconsistent results, and the cost utility of screening has not been assessed.

Methods: An organized screening programme was simulated using Markov modelling in a population aged 50-79 years at 5 year intervals. The programme ended when the subjects reached the age of 80 years. The comparator was opportunistic case finding. The main outcome measures were cases and years of severe visual disability avoided, quality-adjusted life years (QALYs) gained and direct healthcare and non-healthcare costs.

Results: The incremental cost of 1 year of avoided visual disability by screening was $€ 32602$. The cost of one QALY gained by screening was $€ 9023$ with a discount rate of $5 \%$. During the average 20 year time horizon considered, the cumulative incremental costs of screening in a population of 1 million people would be $€ 30$ million, producing 3360 incremental QALYs and 930 years of avoided visual disability for 701 persons. The results were sensitive to the estimates of several parameters, especially screening cost and specificity of screening tests (96-99\% specificity required).

Conclusion: An organized screening programme could be a cost-effective strategy especially in older age groups, in which screening is clearly more likely to be acceptable to decision makers at any level in terms of their willingness to pay for a QALY. Modelling includes some uncertainty especially concerning the specificity of diagnostic tests and screening cost.
\end{abstract}

Key words: Markov model - QALY - visual disability - willingness to pay

Acta Ophthalmol. Scand. 2007: 85: 508-518

(c) 2007 The Authors

Journal compilation $\odot 2007$ Acta Ophthalmol Scand

doi: $10.1111 / j .1600-0420.2007 .00947 . x$

\section{Introduction}

Glaucoma is a chronic progressive optic neuropathy, in which the rate of change of structural and functional abnormalities varies greatly from patient to patient (Heijl et al. 2002; Tuulonen et al. 2003). In the majority of patients the abnormalities progress slowly over a period of years. However, in some patients the disease may lead rapidly to serious visual disability and blindness. Glaucoma reduces patients' health-related quality of life (HRQoL) mainly in far-advanced stages of the disease; in other words, if the visual field damage is severe in both eyes (Tuulonen et al. 2003).

Although the purpose of therapy is to prevent glaucoma-induced visual disability, high-quality studies using severe visual impairment as an endpoint are lacking (Fleming et al. 2005). However, there is evidence of treatment efficacy in primary open angle glaucoma from randomized controlled trials, which have used visual field decay as a surrogate endpoint (Heijl et al. 2002; Maier et al. 2005). The evidence of treatment efficacy in normal tension glaucoma is not consistent (CNTG 1998; Spry et al. 2001; Maier et al. 2005). 
The prevalence of glaucoma increases with age and is approximately $1.5 \%$ in the Caucasian population over 50 years of age (Tuulonen et al. 2003). The ratio of suspected glaucoma to manifest glaucoma has been estimated to be $7: 1$, but can be even higher (Leske \& Hawkins 1994). The introduction of new glaucoma medications has increased annual costs considerably (de Natale et al. 2004), probably because of treating more patients at risk of developing glaucoma rather than those with manifest glaucoma (Tuulonen 2004). Only a few health economic studies have been conducted despite the increasing economic burden of glaucoma (Kobelt 2002; Tuulonen \& Sintonen 2006).

According to epidemiological studies, at least half of subjects with glaucoma are unaware of their disease (Quigley 1996). In most countries glaucoma is usually detected by opportunistic case finding without systematic mass screening programmes. Although several methods are available for glaucoma diagnostics, no single screening test is sufficient to discriminate persons with and without glaucoma (Wormald \& Rauf 1995; Spry et al. 2001). A combination of several tests has been suggested and used in the three studies published on the cost effectiveness of glaucoma screening in the USA, Canada and the UK (Gottlieb et al. 1983; Boivin et al. 1996; Tuck \& Crick 1997). However, the results of these studies are not consistent and none assessed the cost utility of screening.

The purpose of this study is to assess - mainly from the viewpoint of Finnish healthcare system - the cost effectiveness and cost utility of an organized programme for screening and treatment for glaucoma compared to opportunistic case finding.

\section{Methods}

\section{Simulated screening programme}

A screening programme was simulated at 5 year intervals ${ }^{1}$ in a population

\footnotetext{
${ }^{1}$ The rationale behind the 5 year screening interval is as follows. First visual defects are expected to develop in $5 \%$ of subjects with ocular hypertension during the 5 year interval. In patients under treatment, the mean time between the appearance of the first visual changes and blindness is estimated to be 30-40 years (Tuulonen et al. 2003).
}

aged 50-79 years and followed until the age of 89 or death. Thus, the oldest age group of 75-79 years would be invited to screening once and the youngest age group of 50-54 years six times. The examinations carried out in the screening arm were measurement of intraocular pressure, fundus evaluation, ${ }^{2}$ autorefraction and visual field examination. In the positive cases the same tests are carried out anew (second screening) to confirm the findings. Clinical studies have shown that the clinical significance of a single abnormal visual field is small and half of the visual field abnormalities cannot be confirmed when retested (Tuulonen et al. 2003). In the follow-up of diagnosed glaucoma patients, tonometry would be performed twice a year, imaging and automated perimetry once in two years (Tuulonen et al. 2003). The screening arm (Fig. 1) was compared to the current opportunistic case finding in Finland.

\section{Opportunistic case finding in the Finnish healthcare system}

Although the Finnish healthcare system covers the whole population and its services are mainly tax-financed, its main shortcomings are unequal access to care and large variations in the distribution of healthcare services (Isolauri 2000; Keskimäki 2001). The number of visits to the private sector, especially within ophthalmology, has increased constantly since the 1980s. Currently two thirds of all eye

${ }^{2}$ The rationale behind the selected fundus evaluation methods is as follows. Firstly, the wide-angle digital imaging is the same technique that is already used widely and routinely for diabetic screening in Finland. The advantage of imaging compared to ophthalmoscopic evaluation is the documentation of fundus findings for later review. In one wideangle photograph, both optic disc and retinal nerve fibre layer can be evaluated simultaneously. When they are evaluated together with the visual fields, the 'two out of three' rule is applicable - as described in detail in the Finnish Current Care Guideline (Tuulonen et al. 2003) - i.e. options when at least two of three findings in the nerve fibre layer, optic disc and visual field are (ab)normal and concordant. Secondly, the Heidelberg Retina Tomograph is the only one of the new imaging instruments that has been used for screening purposes (Robin et al. 2005). It also images the retinal nerve fibre layer around the optic disc. transactions are performed in the private sector.

Before March 2005 the majority of glaucoma patients did not have access to public care (Brommels et al. 2004). Because the services - mainly paid out of pocket - were delivered in the private sector, very little is known about their content. However, the Social Insurance Institution registers all patients receiving reimbursement for glaucoma medication as well as the number of reimbursed visual field and photographic examinations in the private sector. Based on these data it can be roughly estimated that if all images and visual fields in the private sector were taken because of glaucoma (which is, of course, not the case), only about $15 \%$ of glaucoma patients had their visual fields taken once a year and another $15 \%$ of patients had images taken every 1-2 years together with visual fields.

\section{Markov model}

A Markov model (Treeage Pro 2004; Treeage Software, Williamstown, Massachusetts, USA) was built for economic evaluation including followup and treatment. The model consists of 14 Markov states, which describe all relevant outcomes in the screening and treatment process (Tables 1 and 2, Fig. S1). Simulated cohorts enter the model in states $1,3,4,6,8,10$ and 11 on the basis of estimated prevalence (Table 3). The arm for opportunistic case finding does not include states 2, 5, 9 and 12. The Markov cycle was set at 5 years. Therefore, all transitions from one state to another take place in both arms in 5 year cycles based on 5 year probabilities. Those not participating in screening follow the pathways of opportunistic case finding. The same estimates of prevalence and incidence are used in both arms; similarly, the HRQoL scores and costs associated with the same Markov states in both arms are the same. Screening and treatment affect the probabilities of moving from one state to another and are thus different in the opportunistic case finding arm. The time horizon of the model varied from 40 years in the youngest age group and 10 years in the oldest (some 20 years on average).

All variables in the model were subjected to one-way sensitivity 


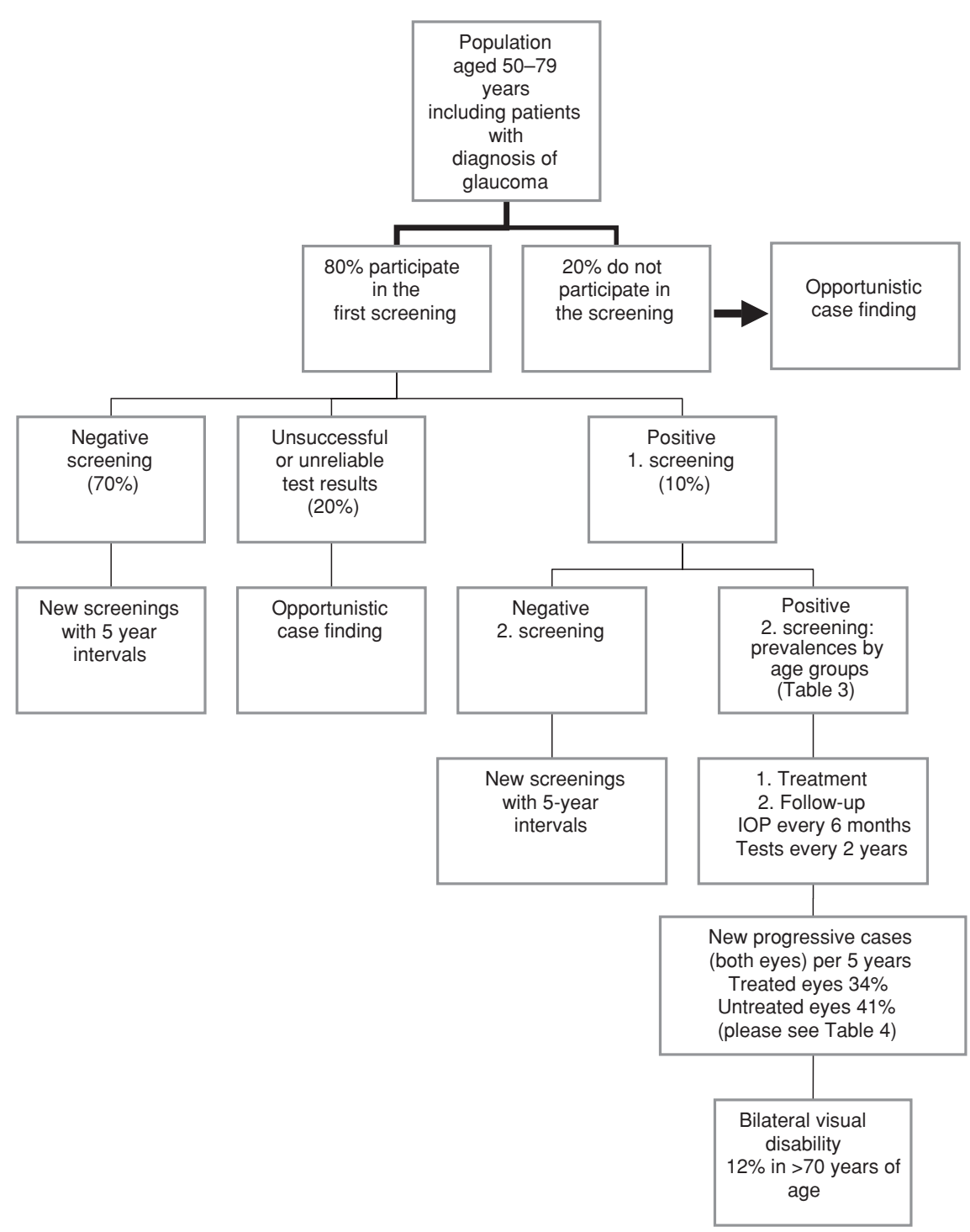

Fig. 1. Flow chart of the simulated screening protocol.

analysis. Threshold analyses were carried out for variables to which the results were most sensitive. Probabilistic sensitivity analysis (10000 Monte Carlo simulations) was performed to evaluate the degree of uncertainty in the results. A normal distribution was assumed for age-specific variables (estimates of prevalence, incidence and HRQoL scores), beta distribution for sensitivity and specificity, and gamma distribution for cost variables. Details of distribution parameters are given in Tables 4 and 5. Results are given as incremental cost-effectiveness and cost-utility ratios (ICER/ICUR), cost-effectiveness plane and costeffectiveness acceptability curves in different age groups. estimated to be six times higher (Tielsch et al. 1991). In the model, only patients with manifest glaucoma ${ }^{3}$ (i.e. not those with ocular hypertension) and false positives produced by screening are treated. The mortality of glaucoma patients was assumed to match the normal population (Grodum et al. 2004). All other probabilities used in the model are given in Table 4.

The resource requirements and costs for the screening programme include personnel, equipment, premises, travelling and (in the case of visual disability) social services (Tables 5 and 6). Therefore, the costs include direct healthcare and non-healthcare costs.

The costs of fundus evaluation were calculated in two ways: (1) for one wide-angle black-and-white red-free image per eye (Tuulonen et al. 1990); and (2) for Heidelberg Retina Tomograph (Robin et al. 2005). The software and hardware for the storage of digital fundus images has been described in detail elsewhere (Tuulonen et al. 2000). The screening costs for perimetry were calculated using both the Humphrey SITA-Fast program (Carl Zeiss Meditec, Dublin, CA, USA) and Frequency Doubling Technology (FDT). The cost per screen was $€ 37$ using Humphrey perimetry and $€ 29$ using FDT (Table 6). Because the screening programme targets mainly older age groups, productivity costs were not included. All costs are in Euro at 2003 price level.

In the base case analysis, costs and health benefits were discounted at $5 \%$ (Ministry of Social Affairs and Health 2004) and at 3.5\%, as per the NICE recommendation (NICE 2004).

The prevalence of glaucoma and diagnosed glaucoma in different age groups was estimated from the equation by Quigley \& Vitale (1997); the prevalence of drug-treated ocular hypertension without glaucoma was estimated using medication reimbursement data from the register of the Finnish Social Insurance Institution (2003) (Table 3).

The 5 year incidences of new glaucoma cases in different age groups were calculated from the age-specific prevalence estimates using the formula $\left(P_{\mathrm{x}+1}-P_{\mathrm{x}}\right) / 1-P_{\mathrm{x}}$, where $P$ denotes prevalence and subscript age group (Leske et al. 1981). The incidence of suspected glaucoma was
${ }^{3}$ The rationale behind treating only patients with manifest glaucoma in the model is as follows. The performance of current glaucoma care can be questioned for several reasons: (1) several epidemiological studies have shown that at least half of glaucoma patients are undiagnosed; (2) simultaneously, more than half of the patients currently treated for glaucoma do not have the disease (Mukesh et al. 2002); and (3) more than half of patients with newly diagnosed glaucoma have seen an ophthalmologist, but their disease was not diagnosed (Grodum et al. 2002; Mukesh et al. 2002). Obviously, if patients with mere risk were treated in the model, it would have affected the cost effectiveness adversely. The main idea in the model was to target the limited resources at finding and treating only those patients with manifest disease. 
Table 1. Definitions of the Markov states and indications of whether the individuals in the screening arm are invited to further screening (S), no further screening (no S) or whether they follow the opportunistic case-finding (OCF) arm.

\begin{tabular}{|c|c|}
\hline Markov state & Description of the state based on data from the Finnish Health 2000 Health Examination Survey $(n=6269)$ \\
\hline (1) Healthy & A person without self-reported glaucoma (S) \\
\hline (2) Healthy, failed screening & ame as (1) but screening failed for one reason or another (OCF) \\
\hline $\begin{array}{l}\text { (3) Suspected glaucoma, } \\
\text { no treatment }\end{array}$ & $\begin{array}{l}\text { A person with self-reported glaucoma (confirmed by an ophthalmologist) and vision at level }<5 \text { on the } 15 \mathrm{D} \\
\text { dimension of vision is followed up by an ophthalmologist, but receives no daily drug treatment and has not } \\
\text { been treated with laser or operation (S) }\end{array}$ \\
\hline $\begin{array}{l}\text { (4) Drug-treated ocular } \\
\text { hypertension, no glaucoma }\end{array}$ & Same as (6) (S or no $\mathrm{S}$ depending on the screening result) \\
\hline $\begin{array}{l}\text { (5) Suspected glaucoma, } \\
\text { failed screening }\end{array}$ & Same as (3) but screening failed for one reason or another (OCF) \\
\hline (6) Drug-treated glaucoma & $\begin{array}{l}\text { A person with self-reported glaucoma (confirmed by an ophthalmologist) and vision at level }<5 \text { on the } 15 \mathrm{D} \\
\text { dimension of vision is followed up by an ophthalmologist, has visited an ophthalmologist less than three } \\
\text { times during the last year and receives daily drug treatment, but has not been treated with laser or } \\
\text { operation (no S) }\end{array}$ \\
\hline $\begin{array}{l}\text { (7) Laser-treated or operated } \\
\text { glaucoma }\end{array}$ & $\begin{array}{l}\text { A person with self-reported glaucoma (confirmed by an ophthalmologist) and vision at level }<5 \text { on the 15D } \\
\text { dimension of vision who has been treated with laser or operation (no S) }\end{array}$ \\
\hline (8) Undiagnosed glaucoma & $\begin{array}{l}\text { A person with self-reported glaucoma (confirmed by an ophthalmologist) and vision at level }<5 \text { on the } 15 \mathrm{D} \\
\text { dimension of vision is not followed up by an ophthalmologist, receives no daily drug treatment } \\
\text { and has not been treated with laser or operation (S) }\end{array}$ \\
\hline $\begin{array}{l}\text { (9) Undiagnosed glaucoma, } \\
\text { failed screening }\end{array}$ & Same as $(8)$ but screening failed for one reason or another $(\mathrm{OCF})$ \\
\hline $\begin{array}{l}\text { (10) Drug-treated glaucoma } \\
\text { with progression }\end{array}$ & $\begin{array}{l}\text { A person with self-reported glaucoma (confirmed by an ophthalmologist) and vision at level }<5 \text { on the } 15 \mathrm{D} \\
\text { dimension of vision is followed up by an ophthalmologist, has visited an ophthalmologist at least three } \\
\text { times during the last year and receives daily drug treatment but has not been treated with laser or } \\
\text { operation (no S) }\end{array}$ \\
\hline $\begin{array}{l}\text { (11) Undiagnosed glaucoma } \\
\text { with progression }\end{array}$ & Same as (8) (S) \\
\hline $\begin{array}{l}\text { (12) Undiagnosed glaucoma } \\
\text { with progression, } \\
\text { failed screening }\end{array}$ & Same as (8) but screening failed for one reason or another (OCF) \\
\hline (13) Severe visual disability & $\begin{array}{l}\text { A person with self-reported glaucoma (confirmed by an ophthalmologist) and vision at level } 5 \text { on the } \\
15 \mathrm{D} \text { dimension of vision (blind or almost blind) (no S) }\end{array}$ \\
\hline
\end{tabular}

$\mathrm{S}$, will be invited to further screening; no $\mathrm{S}$, will not be invited for further screening; OCF, follows the opportunistic case-finding arm. Vision at level 5 on the $15 \mathrm{D}$ dimension of vision $=$ blind or almost blind.

\section{Patient utilities}

The HRQoL scores, measured by the generic 15D instrument (Sintonen 2001; http://www.15D-instrument.net) in the 5 year age groups in different Markov states, were estimated with regression analyses with age, age squared and dummies for Markov states as independent variables. The data (on file) came from the Finnish Health 2000 Health Examination Survey, which was representative of the Finnish population aged 30 years and over $(n=6269)$. The survey respondents were assigned to different Markov states, as described in Table 1. The age-specific HRQoL scores in different Markov states are presented in Table 7.

\section{Results}

The incremental cost of 1 year of avoided visual disability by screening in comparison to opportunistic case finding was $€ 32602$ (ICER of screening). The cost of one quality-adjusted life year (QALY) gained by screening in comparison to opportunistic case finding was $€ 9024$ with a discount rate of $5 \%$ and $€ 7582$ with a discount rate of $3.5 \%$ (ICUR of screening) (Table 8). The cost varied from $€ 52517$ per QALY gained in the youngest cohort to strong dominance in the three oldest cohorts: in these three oldest cohorts, screening strategy was both less costly and more effective than opportunistic case finding.

During the time horizon of the model, in the target population of 1 million the cumulative incremental costs of screening (i.e. costs exceeding opportunistic case finding) would be $€ 30$ million ( $€ 24.5$ million) producing 3360 (6320) incremental QALYs and 930 (3480) years of avoided visual disability by 701 persons (undiscounted values in parentheses).
One-way sensitivity analyses (Table 9) revealed that the results were sensitive to the estimates of specificity of screening tests, screening cost, discount rate, follow-up cost, prevalence of suspected glaucoma and prevalence of glaucoma. The specificities can be only slightly lower than assumed in the base case in younger age groups before screening becomes more costly and less effective. There is much more tolerance in this respect in older age groups (Table 10). Varying participation rates from the baseline $80 \%$ to $60 \%$ and $100 \%$ produced ICERs of $€ 7581$ and $€ 10261$, respectively. The results were quite robust for variation in all other variables, including HRQoL scores.

Probabilistic sensitivity analysis of base case showed that in $24 \%$ of the simulated cases screening was strongly dominant (i.e. both less costly and more effective); screening was more costly and more effective in $47 \%$ of 


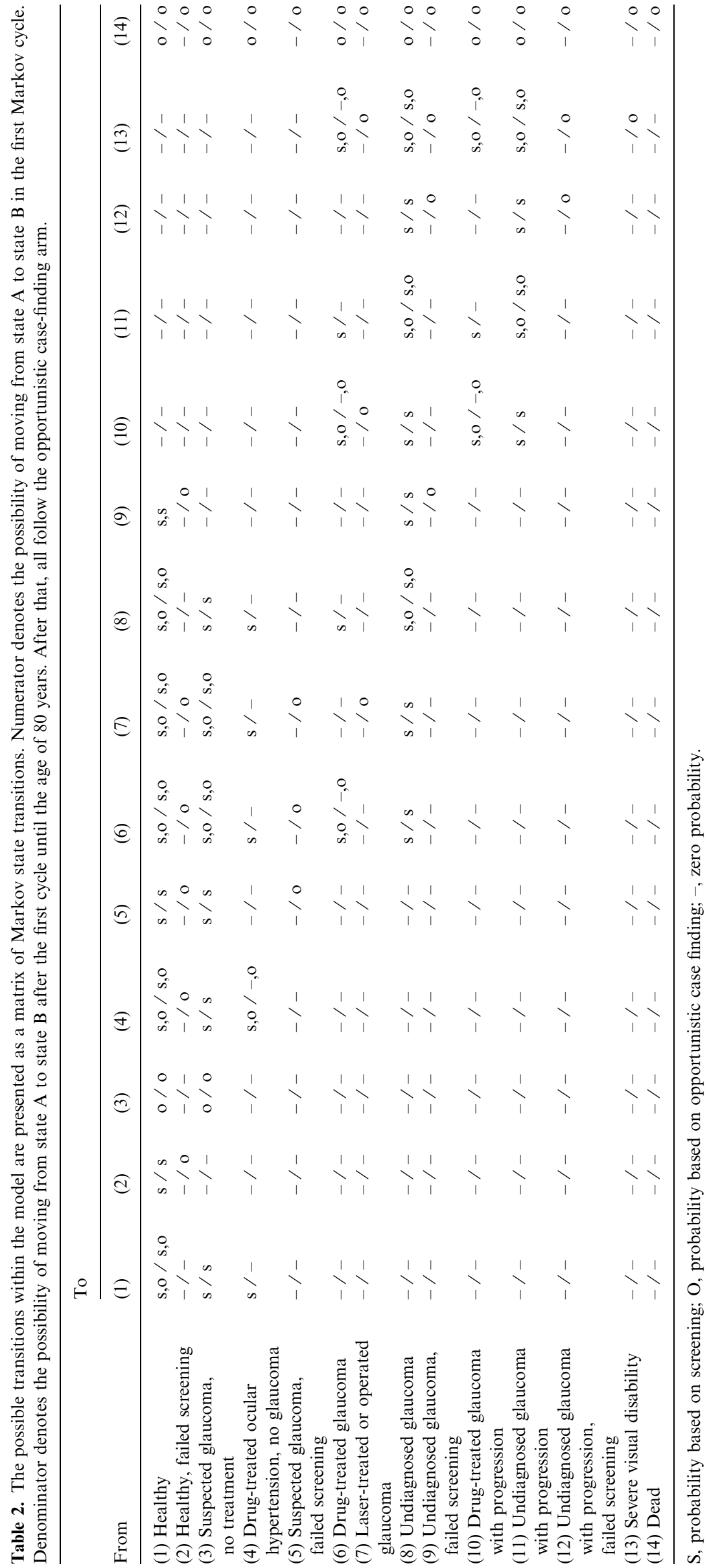

the simulated cases (Fig. 2). In the oldest age group (75-79 years) screening was both less costly and more effective in $80 \%$ of simulated cases; this was true for only $5 \%$ of simulated cases in the youngest age group (50 54 years) (Fig. 3). Cost-effectiveness acceptability curves in Fig. 4 reveal clearly the big differences between the age groups in the probability of screening being considered cost effective. At any level of societal willingness to pay for a QALY, the probability of screening being acceptable is clearly higher in older age groups.

\section{Discussion}

\section{Main findings}

Our analysis suggests that an organized glaucoma screening programme, as outlined earlier in this article, could be a cost-effective strategy compared to opportunistic case finding in Finland, especially in older age groups. However, this conclusion is to some extent surrounded by uncertainty and depends largely on the high specificity of screening tests. In younger age groups the specificity can be only slightly lower than assumed in the base case analysis before screening becomes more costly and less effective. In older groups there is more tolerance in this respect (Table 10). At any level of decision makers' willingness to pay for a QALY, the probability of screening being acceptable to them is clearly higher in older age groups (Fig. 4).

There are rather obvious reasons for this perhaps counterintuitive result. The oldest age groups have a much higher prevalence and incidence of progressive manifest glaucoma than the younger age groups. Simultaneously, the older subjects also have a higher probability of being treated for ocular hypertension without glaucoma (Table 3). Because the oldest age groups are screened in the model only once (75-79 years) or twice (70-74 years), the cases with manifest glaucoma will be found and treated, and will have time to benefit from treatment. In the model, therapy will not be initiated or will be withdrawn from patients with ocular hypertension. This approach of treating only manifest glaucoma (i.e. not the risk of the disease) saves a lot of 
Table 3. The age-specific prevalence estimates serving as probabilities of entry to the screening and opportunistic case-finding arms: (1) estimated prevalence of glaucoma according to Quigley \& Vitale (1997); (2) prevalence of currently diagnosed glaucoma (cases identified by the opportunistic case finding, i.e. $50 \%$ of prevalent cases); (3) in the opportunistic case-finding arm, the prevalence of drug-treated ocular hypertension without glaucoma (Social Insurance Institution 2003).

\begin{tabular}{llll}
\hline Age group & $\begin{array}{l}\text { Prevalence of } \\
\text { glaucoma (\%) }(1)\end{array}$ & $\begin{array}{l}\text { Prevalence of diagnosed } \\
\text { glaucoma (\%) (2) }\end{array}$ & $\begin{array}{l}\text { Drug-treated hypertension, } \\
\text { no glaucoma (\%) (3) }\end{array}$ \\
\hline $50-54$ & 0.7 & 0.4 & 0.2 \\
$55-59$ & 1.0 & 0.5 & 0.5 \\
$60-64$ & 1.4 & 0.7 & 1.2 \\
$65-69$ & 2.0 & 1.0 & 2.0 \\
$70-74$ & 2.8 & 1.4 & 3.6 \\
$75-79$ & 3.7 & 1.9 & 5.5 \\
$80-84$ & 4.8 & 2.4 & 7.4 \\
$85-89$ & 6.1 & 3.1 & 15.8 \\
\hline
\end{tabular}

money without sacrificing a great deal of benefit in the oldest age groups.

On the other hand, the younger age groups have a low prevalence and incidence of glaucoma and their disease - on average - progresses slower than in the older patients with more severe damage. Because the younger patients attend screening several times, they incur substantial costs without benefiting much until their older years. Because of discounting, this benefit is further reduced considerably. The cost-effectiveness acceptability curve in the oldest age group is almost horizontal at the probability level of close to 1 (Fig. 4) because screening is strongly dominant in this age group. Screening produces net benefits at the same time as it saves costs $(80 \%$ of simulated cases are in Quadrant IV in Fig. 3). Therefore, screening is worth implementing regardless of the level of willingness to pay because it would free resources for other uses.

\section{Strengths of the study}

To our knowledge, this is the first published study applying Markov modelling to assess the cost utility of glaucoma screening and use a generic quality of life instrument that allows comparisons across different conditions. Because of a lack of adequate evidence on the values of most of the important parameters, a model was built to explore the effect of these parameters and the uncertainty around them on the cost utility of screening.

The model considers the whole chain of outcomes from screening to visual disability and similarly the full range of costs associated with this chain. The effects of assumptions and uncertainties were tested extensively

Table 4. Probabilities (\%) used in the Markov model.*

\begin{tabular}{|c|c|c|c|}
\hline Variable & Base case analysis & Range for sensitivity analysis & Distribution parameters for PSA \\
\hline Sensitivity of 1 st screening $^{1}$ & 85 & $60-95$ & Beta $(68,12)$ \\
\hline Specificity of 1 st screening ${ }^{1}$ & 90 & $75-99$ & Beta $(72,8)$ \\
\hline Specificity of 2 nd screening ${ }^{1}$ & 80 & $70-90$ & Beta $(128,32)$ \\
\hline Overall sensitivity after 1 st and 2 nd screening & 84 & & \\
\hline Overall specificity after 1 st and 2 nd screening & 98 & & \\
\hline Screening failure ${ }^{1}$ & 20 & $0-40$ & Beta $(40,160)$ \\
\hline Prevalence of glaucoma ${ }^{2}$ & See Table 3 & \pm 50 & Normal (prevalence, $0.1 \times$ prevalence) \\
\hline Prevalence of suspected glaucoma ${ }^{3}$ & 4 & $2-6$ & Beta $(40,960)$ \\
\hline $\begin{array}{l}\text { Overall prevalence of severe visual disability } \\
\text { among glaucoma patients aged over } 70 \text { years }\end{array}$ & 12 & $8-16$ & Normal (prevalence, $0.1 \times$ prevalence) \\
\hline Incidence of glaucoma ${ }^{5}$ & $\dagger$ & \pm 50 & Normal (incidence, $0.1 \times$ incidence) \\
\hline $\begin{array}{l}\text { Progressive changes* for treated eyes per } 5 \text { years }^{6} \\
\quad \text { (both eyes) }\end{array}$ & 34 & $18-45$ & Normal $(0.34,0.034)$ \\
\hline $\begin{array}{l}\text { Probability of glaucoma patients undergoing laser } \\
\text { or surgical procedures }\end{array}$ & 6.75 & $3.4-10.1$ & Normal $(0.0675,0.068)$ \\
\hline
\end{tabular}

PSA, probabilistic sensitivity analysis.

Sources: ${ }^{1}$ Tuulonen et al. (2003); ${ }^{2}$ Quigley \& Vitale (1997); ${ }^{3}$ Mitchell et al (1996); ${ }^{4}$ Hirvelä (1995); ${ }^{5}$ Leske et al. (1981); ${ }^{6}$ Heijl et al. (2002), CNTG (1998); ${ }^{7}$ Finnish Health Care Register (2003).

*The rationale for progression rates is as follows. The evidence of early, moderate and advanced stages of glaucoma in the population-based studies is extremely limited and variable regarding how these stages are defined, how long glaucoma patients stay in each state and what is the proportion of glaucoma patients in each state. Instead of trying to make the best educated guess of these factors and increasing the complexity of the model, we decided to assume a linear manner of progression and estimated the progression rates from the two treatment-no treatment studies (CNTG 1998, Heijl et al. 2002). However, in these randomized controlled trials (i.e. in ideal settings) the progression rates were reported for one eye only (i.e. not per patients' two eyes, which determines both the HRQoL and visual disability). It is very hard to say whether the estimates of our model reflect the real world because the results for CNTS were reported in eight different ways with very variable progression rates between treated and non-treated eyes. There is a lack of adequate evidence on the values of most of the important parameters needed in the model.

${ }^{\dagger}$ See Data sources and assumptions. 
Table 5. Input cost data used in the model.

\begin{tabular}{|c|c|c|c|c|}
\hline Variable & Description & Cost $(€)$ & $\begin{array}{l}\text { Range for sensitivity } \\
\text { analysis }(€) \text { and } \\
\text { parameters of gamma } \\
\text { distribution }(\alpha, \beta) \text { in PSA }\end{array}$ & Source \\
\hline Cost of follow-up & $\begin{array}{l}\text { The mean cost of follow-up, } \\
\text { including all examinations }\end{array}$ & $256 /$ year & $120-400(11.65,22)$ & $\begin{array}{l}\text { Finnish Health Care } \\
\text { Registry (2003) }\end{array}$ \\
\hline $\begin{array}{l}\text { Cost of glaucoma } \\
\text { medication }\end{array}$ & $\begin{array}{l}\text { Mean cost of glaucoma medication. } \\
\text { For laser-treated or operated } \\
\text { patients it was assumed that } \\
\text { medication cost is } 50 \% \text { of mean } \\
\text { cost for first } 5 \text { years, } 70 \% \text { for next } \\
5 \text { years and then } 100 \%\end{array}$ & $302 /$ year & $200-400(12,25)$ & $\begin{array}{l}\text { Finnish Social } \\
\text { Insurance } \\
\text { Institution (2003) }\end{array}$ \\
\hline $\begin{array}{l}\text { Cost of glaucoma } \\
\text { operation }\end{array}$ & $\begin{array}{l}\text { Weighted mean cost of laser therapy } \\
\text { (unit cost } € 146 \text { ) and glaucoma } \\
\text { operation (unit cost } € 1333 \text { ) }\end{array}$ & 614 & $300-1000(20,30)$ & $\begin{array}{l}\text { Finnish Health } \\
\text { Care Register (2003) }\end{array}$ \\
\hline Cost of screening & See Table 6 & 37 & $15-100(6,6.2)$ & \\
\hline $\begin{array}{l}\text { Cost of visual } \\
\text { disability }\end{array}$ & $\begin{array}{l}\text { Direct visual disability-related } \\
\text { costs of diabetic patients } \\
\text { (assumed to be similar in } \\
\text { glaucoma-induced visual disability) }\end{array}$ & 11867 / year & $6000-18000(10,1186.7)$ & Pajunpää (1999) \\
\hline
\end{tabular}

PSA, probabilistic sensitivity analysis.

Table 6. Resource requirements and costs of carrying out annually 269300 primary screenings and 27000 secondary screenings in 14 screening centres throughout the country.

\begin{tabular}{|c|c|c|}
\hline Resource & Units & Unit cost $(€ /$ year $)$ \\
\hline \multicolumn{3}{|l|}{ Medical staff* } \\
\hline Nurses & & $31600 \dagger$ \\
\hline Humphrey + digital camera or HRT & 167 & \\
\hline FDT + digital camera or HRT & 104 & \\
\hline Secretaries & 32 & $28600 \dagger$ \\
\hline Ophthalmologists & 5 & $82000 \dagger$ \\
\hline \multicolumn{3}{|l|}{ Equipment } \\
\hline Humphrey visual field instruments & 77 & $5198 \ddagger$ \\
\hline FDT visual field instruments & 14 & $3100 \ddagger$ \\
\hline Digital cameras & 31 & $6930 \ddagger$ \\
\hline Heidelberg Retina Tomograph III & 31 & $8201 \ddagger$ \\
\hline Digital imaging and information systems & 31 & $11550 \ddagger$ \\
\hline Autorefractometers & 14 & $2300 \ddagger$ \\
\hline Slits lamps & 14 & $3580 \ddagger$ \\
\hline \multicolumn{3}{|l|}{ Other costs } \\
\hline Overall expenses & 269300 & 2 \\
\hline Rent of 14 screening centres§ & 14 & \\
\hline Humphrey + digital camera or HRT & & 16926 \\
\hline FDT + digital camera or HRT & & 9085 \\
\hline Travelling & 269300 & $5.90 \pi$ \\
\hline $\begin{array}{l}\text { Cost per screen using Humphrey }+ \text { digital camera } \\
\text { or HRT }\end{array}$ & & 37 \\
\hline Cost per screen using FDT + digital camera or HRT & & 29 \\
\hline
\end{tabular}

*(a) 210 working days per year; (b) 38.25 working hours per week for nurses and secretaries, 37 hours per week for ophthalmologists; (c) time required per person screened during the first screening: nurse/photographer 55 min (imaging, visual field examination and intraocular pressure measurement), secretary $10 \mathrm{~min}$, ophthalmologist $1 \mathrm{~min}$ (analysis of test results); (d) time required per person screened in the second screening: nurse/photographer 45 min (imaging, visual field examination and intraocular pressure measurement), secretary $10 \mathrm{~min}$, ophthalmologist 6 min (analysis of test results).

$\uparrow$ Annual gross salary including social security expenses of $35 \%$.

$¥$ Annuity with lifespan of 5 years, interest rate of $5 \%$ and scrap value of 0 .

$\S$ Based on average all-inclusive (heating, electricity etc) rent $/ \mathrm{m}^{2}$ of premises (Statistics of Finland). ๆHujanen (2003).

with sensitivity analyses. They revealed that the cost utility of an organized screening programme is

\section{Limitations of the study}

An economic evaluation of glaucoma screening typically encounters several difficult problems. Diagnostic studies of glaucoma lack a generally approved definition of the disease (Bathija et al. 1998). Because of different definitions, studies also offer variable estimates for prevalence and incidence. Moreover, a majority of diagnostic studies have been performed on preselected patient populations, which may lead to over-optimistic results (Siddiqui et al. 2005).

The estimates of the sensitivity and specificity of diagnostic tests vary substantially in the literature. Our estimates are based on an earlier systematic review of the literature, the Finnish EBM Guideline for Glaucoma (Tuulonen et al. 2003). However, no meta-analyses were undertaken to obtain the values for sensitivity and specificity for the different tests. Our results are based on the optimistic assumption that evaluating information from three different examinations (nerve fibre layer, optic disc and visual field) (Tuulonen et al. 2003; Robin et al. 2005) would bring specificity and sensitivity to an acceptable level. Compared to studies performed in academic centres, in everyday practice ophthalmologists often apply a nonoptimal combination of diagnostic and follow-up tests and do so far less frequently, leading to a low specificity. Therefore, the current opportunistic case finding produces a large number 
Table 7. The health-related quality of life (HRQoL) scores in different Markov states and age groups (for descriptions of Markov states, see Table 1).

\begin{tabular}{lllllll}
\hline & \multicolumn{2}{l}{ Markov states } & & & \\
\cline { 2 - 7 } Age group & 1,2 & 3,5 & 4,6 & 7 & $8,9,11,12$ & 10 \\
\hline $50-54$ & 0.916 & 0.905 & 0.903 & 0.904 & 0.894 & 0.893 \\
$55-59$ & 0.909 & 0.897 & 0.896 & 0.896 & 0.887 & 0.885 \\
$60-64$ & 0.894 & 0.882 & 0.881 & 0.882 & 0.872 & 0.870 \\
$65-69$ & 0.871 & 0.859 & 0.858 & 0.859 & 0.849 & 0.743 \\
$70-74$ & 0.840 & 0.828 & 0.827 & 0.828 & 0.818 & 0.723 \\
$75-79$ & 0.801 & 0.790 & 0.788 & 0.789 & 0.779 & 0.707 \\
$80-84$ & 0.755 & 0.743 & 0.742 & 0.743 & 0.733 & 0.778 \\
$85-89$ & 0.700 & 0.689 & 0.687 & 0.688 & 0.678 & 0.731 \\
\hline
\end{tabular}

Table 8. Base case results.

\begin{tabular}{|c|c|c|c|c|c|c|c|c|}
\hline Strategy & $\begin{array}{l}\text { Cost }(€) \\
(1)\end{array}$ & $\begin{array}{l}\text { Incremental } \\
\text { cost }(€) \\
(2)\end{array}$ & $\begin{array}{l}\text { QALYs } \\
\text { (3) }\end{array}$ & $\begin{array}{l}\text { Incremental } \\
\text { QALYs } \\
\text { (4) }\end{array}$ & $\begin{array}{l}\text { ICUR }(€) \\
(2) /(4)\end{array}$ & $\begin{array}{l}\text { Years of } \\
\text { visual disability } \\
\text { (6) }\end{array}$ & $\begin{array}{l}\text { Years of } \\
\text { visual disability } \\
\text { avoided } \\
\text { (7) }\end{array}$ & $\begin{array}{l}\text { ICER }(€) \\
(2) /(7)\end{array}$ \\
\hline anistic case finding & 853.00 & & 10.13495 & & & 0.02715 & & \\
\hline Screening & 883.32 & 30.32 & 10.13831 & 0.00336 & 9024 & 0.02622 & 0.00093 & 32602 \\
\hline
\end{tabular}

QALYs, quality-adjusted life years; ICUR, incremental cost-utility ratio; ICER, incremental cost-effectiveness ratio.

Table 9. Results of one-way sensitivity analysis.

\begin{tabular}{|c|c|c|c|c|}
\hline Variable & Range & $\begin{array}{l}\text { ICUR* for lower } \\
\text { bound of range }\end{array}$ & $\begin{array}{l}\text { ICUR for upper } \\
\text { bound of range }\end{array}$ & Remarks \\
\hline Discount rate & $0-0.1$ & $€ 3877$ & $€ 13734$ & $3.5 \%: € 7582$ \\
\hline Follow-up cost & $€ 120-€ 400$ & $€ 16581$ & $€ 1021$ & \\
\hline Prevalence of glaucoma & $\pm 50 \%$ & $€ 4506$ & $€ 38047$ & From Quigley \& Vitale (1997) \\
\hline Prevalence of suspected glaucoma & $0.02-0.06$ & $€ 34552$ & Screening dominant & \\
\hline Screening cost & $€ 15-€ 100$ & Screening dominant & $€ 20634$ & Threshold value: $€ 19$ \\
\hline $\begin{array}{l}\text { Overall specificity of two serial } \\
\text { screening tests }\end{array}$ & $0.925-0.999$ & Screening dominated & Screening dominant & $\begin{array}{l}\text { Specificity of } 1 \text { st screening test: } 0.75-0.99 \\
\text { Specificity of } 2 \text { nd screening test: } 0.70-0.90\end{array}$ \\
\hline
\end{tabular}

*Incremental cost-utility ratio (ICUR): $\Delta \mathrm{C} / \Delta \mathrm{E}$, where $\Delta \mathrm{C}$ is incremental cost of screening compared to opportunistic case finding (OCF) and $\Delta \mathrm{E}$ is incremental effectiveness (in terms of quality-adjusted life years gained) of screening compared to OCF. Screening is (strongly) dominant if screening is less costly and more effective than OCF and (strongly) dominated in the opposite case.

Table 10. Threshold analyses by age cohorts: screening dominant within the range of the variables.

\begin{tabular}{llllllll}
\hline & & & & & & & Overall specificity of two serial screening tests \\
\cline { 5 - 7 } Age cohort & $\begin{array}{l}\text { Discount } \\
\text { rate }\end{array}$ & $\begin{array}{l}\text { Follow-up } \\
\text { cost }\end{array}$ & $\begin{array}{l}\text { Prevalence of } \\
\text { glaucoma }\end{array}$ & $\begin{array}{l}\text { Prevalence of } \\
\text { suspected } \\
\text { glaucoma }\end{array}$ & $\begin{array}{l}\text { Screening } \\
\text { cost }\end{array}$ & Screening dominated & Screening dominant \\
\hline $50-54$ years & No & No & No & No & No & $<0.975$ & $>0.991$ \\
$55-59$ years & No & No & No & No & No & $<0.963$ & $>0.988$ \\
$60-64$ years & $<0.01$ & $>€ 371$ & No & $>0.05$ & $<€ 23$ & $<0.954$ & $>0.983$ \\
$65-69$ years & $<0.095$ & $>€ 172$ & $<+50 \%$ & Yes & $<€ 50$ & $<0.941$ & $>0.975$ \\
$70-74$ years & Yes & Yes & $<+50 \%$ & Yes & $<€ 78$ & $<0.919$ & $>0.961$ \\
$75-79$ years & Yes & Yes & $<+50 \%$ & Yes & Yes & $<0.881$ & $>0.943$ \\
\hline
\end{tabular}

of non-glaucomatous subjects, who are treated for glaucoma. For instance, in Finland there are already more individuals on glaucoma medication than there should be 'true' glaucoma patients on the basis of epidemiological studies (Table 3), and yet only half of patients with manifest glaucoma have been diagnosed. In our model, the non-glaucomatous individuals on medication were screened in order to better target the treatment to the 'right' subjects - patients with manifest glaucoma. Whether this approach would be justified in the real world is, of course, an ethical question that should be considered alongside cost-effectiveness issues.

We had to assume that the technology, effect of therapy, relative prices, demography and life expectancy would 


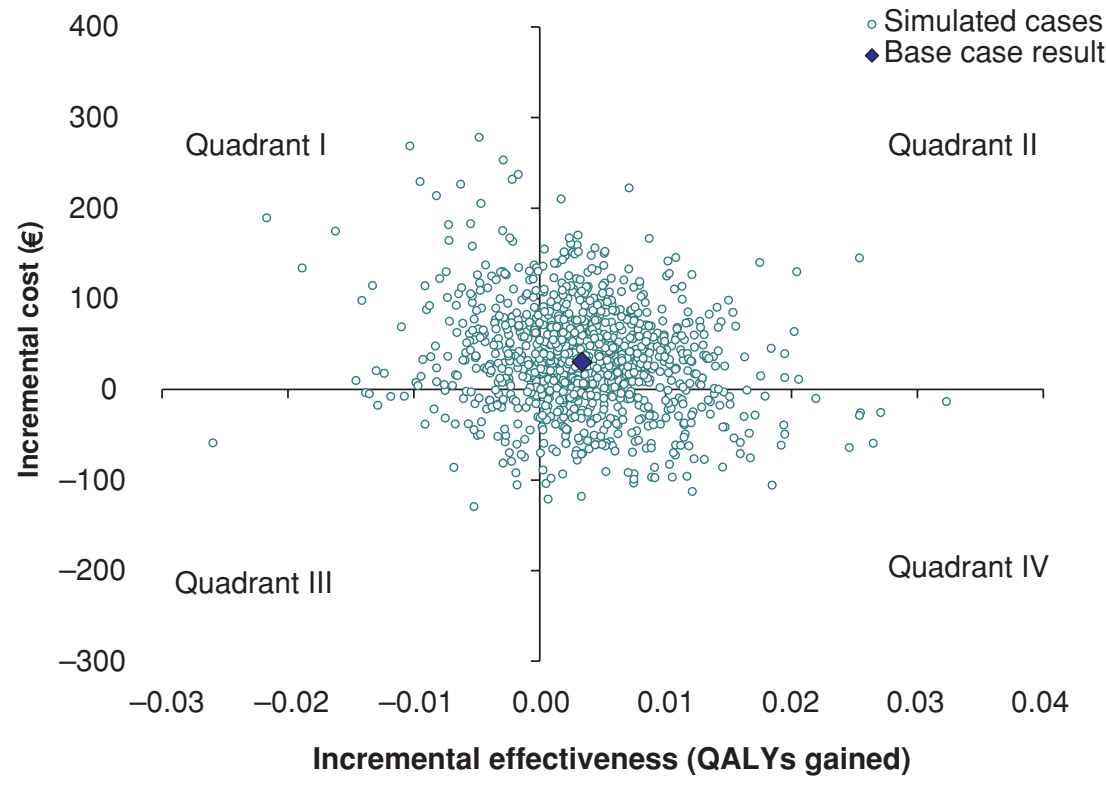

Fig. 2. Cost-effectiveness plane in the base case analysis (5 year age groups between 50 and 79 years are invited to screening at 5 year intervals, input parameters in Tables 3-6). In 24\% of simulated cases, screening was both less costly and more effective (quadrant IV); in $7 \%$ of simulated cases, screening was less costly and less effective (quadrant III); in $47 \%$ of simulated cases, screening was more costly and more effective (quadrant II); in $22 \%$ of simulated cases, screening was more costly and less effective (quadrant I).

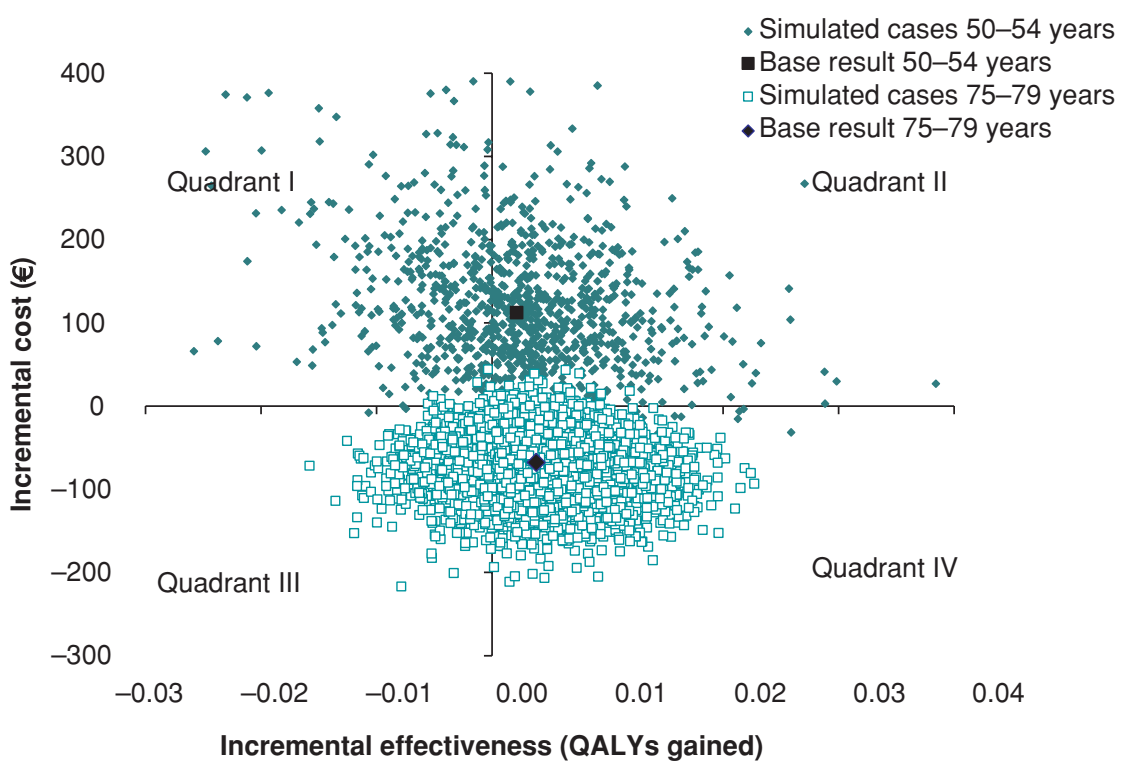

Fig. 3. Cost-effectiveness plane comparing age groups 50-54 (invited to screening six times) and 75-79 years (invited to screening once; input parameters in Tables 3-6). In age group 7579 years screening was both less costly and more effective in $80 \%$ of simulated cases (quadrant IV); in $19 \%$ of simulated cases, screening was less costly and less effective (quadrant III); in $1 \%$ of simulated cases, screening was more costly and more effective (quadrant II); in $0.2 \%$ of simulated cases, screening was more costly and less effective (quadrant I). In age group 50-54 years the rates were $5 \%, 2 \%, 57 \%$ and $37 \%$, respectively.

remain unchanged over the 10-40 year time horizon of the model. This assumption will hardly hold in reality.

The HRQoL scores associated with different Markov states were estimated from a representative population health survey and were based on self-reported diagnosis and use of medication and other treatments. According to the survey respondents, their diagnosis was confirmed by an ophthalmologist, but obviously the method of confirmation is not known. Besides, the data did not allow a distinction between the states with and without progression. Therefore, we used the same HRQoL score in both progressive and non-progressive cases. Although counterintuitive, this assumption is, at least in early glaucoma, supported by the Early Manifest Glaucoma Trial Group report, in which Hyman et al. (2005) found that visual field defect progression did not affect vision-targeted HRQoL until visual acuity was affected or with increase of the mean deviation of the better eye. This pattern is also clear in the HRQoL scores we derived. Although Kobelt et al. (2006) found a decrease in the HRQoL scores with increasing glaucomatous damage (stages 1-4), the difference was statistically significant only in the most severe glaucoma (stage 5). Besides, sensitivity analyses confirmed that the base case results are quite robust to variation in the quality of life scores within their confidence intervals.

Moreover, our data produced a slightly higher HRQoL score for the state 'undiagnosed glaucoma with progression' than for the state 'drugtreated glaucoma with progression'. It is difficult to judge whether this is a real difference (e.g. because of sideeffects or nuisance caused by therapy and frequent follow-up visits, or consciousness of suffering from a progressive disease) or an artefact of our data. However, this difference was very small and the results of probabilistic sensitivity analysis confirmed the insignificance of the difference. In cases of diagnosed early glaucoma, vision-targeted HRQoL have been reported to be similar for treated and untreated patients (Hyman et al. 2005).

\section{Comparison to previous literature}

For several reasons, it is difficult to compare our results with earlier findings. Gottlieb et al. (1983) concluded that the cost per year of vision saved was lowest in the group aged 55-70 and screening targeted only at the over 70 age groups was probably not cost effective. In contrast, screening in our model becomes more cost effective 


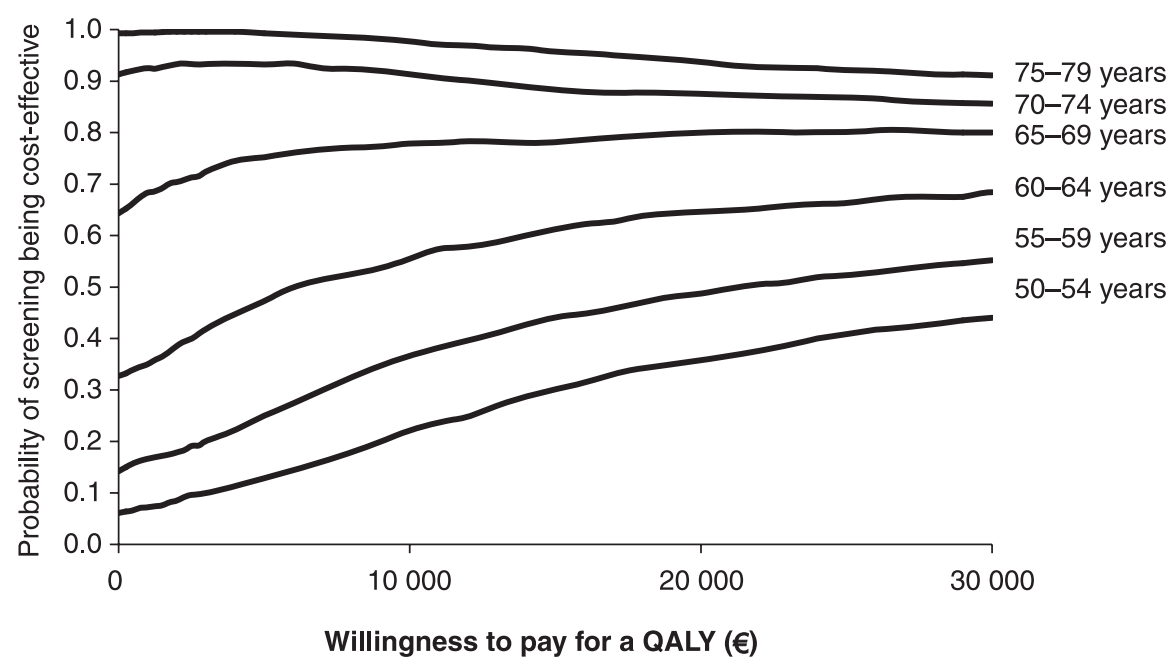

Fig. 4. Cost-effectiveness acceptability curves in different age groups.

with increasing age. This discrepancy can be explained by a host of differences in data and methodology, such as measure of effectiveness, screening frequency [Gottlieb et al. (1983) screened only once in each age group] and estimates of prevalence (ours are about double). Moreover, Gottlieb et al. (1983) did not consider the cost of blindness that would be saved if blindness is prevented.

In a Canadian study, modelling was used to project the effectiveness and costs of 12 screening scenarios (Boivin et al. 1996). The conclusion was that cost effectiveness of most screening programmes considered would not be competitive, but screening is presumably more cost effective when it is limited to older age groups (65-79 years) and carried out less frequently. This conclusion is basically in line with ours, although the authors used a narrow measure of effectiveness (years of blindness avoided) and more frequent screening.

Tuck \& Crick (1997) estimated the cost per true positive case using different combinations of three main tests (ophthalmoscopy, tonometry and perimetry). However, they did not consider the costs and effectiveness of follow-up and treatment and thus addressed a different issue to that considered here.

\section{Meaning of the study}

The study shows that the cost utility of glaucoma screening depends essentially on the screening cost and specificity of diagnostic tests, but also on several other parameters. Great attention should be paid to getting realistic estimates for these parameters. Policy makers can use the results and model to choose which (if any) age groups are appropriate for screening given their willingness to pay for a QALY or avoided visual disability.

Unanswered questions and future research The generalizability of the results should be evaluated in other settings while considering local features, such as systems of opportunistic case finding. A randomized screening trial run in several European countries would be the best study design and give the most reliable evidence of the cost effectiveness of screening in preventing glaucoma-induced visual disability. Simultaneously, the sensitivity and specificity of diagnostic tests and their combinations could be evaluated in large non-selected populations. Establishing a gold-standard definition of glaucoma would be essential.

The HRQoL scores associated with different Markov states should be measured directly with a generic instrument applicable to cost-utility analysis among an adequate number of individuals assigned by ophthalmologists to these states. That would certainly add credibility to the results.

\section{Acknowledgements}

This study was funded by the Finnish Office for Health Technology Assessment (FinOHTA). Professor Marjukka
Mäkelä of the FinOHTA has contributed in the planning phase of the study.

\section{Supplementary Material}

The following supplementary material is available for the article online:

Figure S1: The Markov model.

This material is available as part of the online article from http:// www.blackwell-synergy.com/doi/aos/ 10.1111/j.1600-0420.2007.00947.x

Please note: Blackwell Publishing are not responsible for the content or functionality of any supplementary materials supplied by the authors. Any queries (other than missing material) should be directed to the corresponding author for the article.

\section{References}

Bathija R, Gupta N, Zangwill L \& Weinreb RN (1998): Changing definition of glaucoma. J Glaucoma 7: 165-169.

Boivin JF, McGregor M \& Archer C (1996): Cost effectiveness of screening for primary open angle glaucoma. J Med Screening 3: 154-163.

Brommels M, Jouttimäki R-M \& Myllymäki K (2004): National project to secure the future of health care. Access to health care and waiting list management. Memorandum 2003:33. Helsinki: Ministry of Social Affairs and Health.

Collaborative Normal Tension Glaucoma Study Group (1998): Comparison of glaucomatous progression between untreated patients with normal-tension glaucoma and patients with therapeutically reduced intraocular pressure. Am J Ophthalmol 126: $487-497$.

Fleming C, Whitlock E, Beil T \& Smit B (2005): Primary care screening for ocular hypertension and primary open-angle glaucoma. Evidence synthesis 34 (contract no. 290-02-0024), Oregon Evidence-Based Practice Center. Available online at http:// www.ahrq.gov/clinic/uspstf05/glaucoma/ glaucsyn.pdf.

Finnish Statistics on Medicine 2003 (2004): Helsinki Finland Agency for Medicines and Social Insurance Institution, Edita Inc.

Gottlieb LK, Schwartz B \& Pauker S (1983): Glaucoma screening. Cost-effectiveness analysis. Surv Ophthalmol 28: 206-227.

Grodum K, Heijl A \& Bengtsson B (2004): Glaucoma and mortality. Graefe's Arch Clin Exp Ophthalmol 242: 397-401.

Grodum K, Heijl A \& Bengtsson B (2002): A comparison of glaucoma patients identified through mass screening and in clinical routine practice. Acta Ophthalmol Scand 80 627-631. 
Heijl A, Leske MC, Bengtsson B, Hyman L, Bengtsson B, Hussein M \& Early Manifest Glucoma Trial Group (2002): Reduction of intraocular pressure and glaucoma progression. Results from the Early Manifest Glaucoma Trial. Arch Ophthalmol 120: 1268-1279.

Hirvelä H (1995): Visual function and ocular disease in the elderly. The Oulu study. Acta Universitatis Ouluensis Series D Medica 327. 86(40)s. ISSN 0355-3221.

Hujanen T (2003): Unit costs in Finnish health care in 2001. Helsinki: Stakes Aiheita.

Hyman LG, Komaroff E, Heijl A, Bengtsson B, Leske MC \& the Early Manifest Glaucoma Trial Group (2005): Treatment and vision-related quality of life in the early manifest glaucoma trial. Ophthalmology 112: $1505-1513$.

Isolauri J (2000): Health care into the 21st century. Production and availability of specialised health care services in different parts of Finland in 1999. Working Group Memorandums of the Ministry of Social Affairs and Health, no. 21. Helsinki: Ministry of Social Affairs and Health.

Keskimäki I (2001): How did Finland's economic recession in the early 1990s affect socio-economic equity in the use of hospital care? In: Keskimäki I \& Häkkinen U (eds) Economic recession in Finland in the early 1990s and changes in the use of health services. Themes from Finland 4/2001. Helsinki: National Research and Development Centre for Welfare and Health, 23-40.

Kobelt G (2002): Glaucoma care updates. Health economics, economic evaluation, and glaucoma. J Glaucoma 11: 531-539.

Kobelt G, Jonsson B, Bergstrom A, Chen E, Linden C \& Alm A (2006): Cost-effectiveness analysis in glaucoma: what drives utility? Results from a pilot study in Sweden. Acta Ophthalmol Scand 84: 363-371.

Leske MC, Ederer F \& Podgor M (1981): Estimating incidence from age-specific prevalence in glaucoma. Am J Epidemiol 113 606-613.

Leske MC \& Hawkins B (1994): Screening: relationship to diagnosis and therapy. In Duane TD (ed) Clinical ophthalmology, vol. 5. Philadelphia: Harper \& Row, 54 $1-19$.

Maier PC, Funk J, Schwarzer G \& FalckYtter YT (2005): Treatment of ocular hypertension and open angle glaucoma: meta-analysis of randomized controlled trials. BMJ 331: 134.

Ministry of Social Affairs and Health (2004): Guidelines for preparing a health economic evaluation (annex to the decree 1357/2004). Available online at http:// www.stm.fi/Resource.phx/eng/orgis/board/ pharmaboard/legislation.htx.i197.pdf.

Mitchell P, Smith W, Attebo K \& Healey PR (1996): Prevalence of open-angle glaucoma in Australia. The Blue Mountains eye study. Ophthalmology 103: 1661-1669.

Mukesh BN, McCarty CA, Rait JL \& Taylor HR (2002): Five year incidence of openangle glaucoma: the visual impairment project. Ophthalmology 109: 1047-1051.

de Natale R, Draghi E \& Dorigo MT (2004): How prostaglandins have changed the medical approach to glaucoma and its costs: an observational study of 2228 patients treated with glaucoma medications. Acta Ophthalmol Scand 82: 393396.

National Institute for Clinical Excellence (NICE) (2004) NICE guide to the methods of technology appraisal. London: NICE.

Pajunpää H (1999): The costs of photographic screening for diabetic retinopathy and the quality of life and mortality of visually disabled patients. Acta Universitatis Ouluensis Medica 522. 115 (62)s. ISSN 03553221

Quigley HA (1996): Number of people with glaucoma worldwide. Br J Ophthalmol 80: 389-393.

Quigley HA \& Vitale S (1997): Models of open-angle glaucoma prevalence and incidence in the United States. Invest Ophthalmol Vis Sci 38: 83-91.

Robin TA, Muller A, Rait J, Keeffe JE \& Taylor HR (2005): Performance of community-based glaucoma screening using frequency doubling technology and Heidelberg retina tomography. Ophthalmic Epidemiol 12: 167-178.

Siddiqui MA, Azuara-Blanco A \& Burr J (2005): The quality of reporting of diagnostic accuracy studies published in ophthalmic journals. Br J Ophthalmol 89: 261-265.

Sintonen H (2001): The 15D instrument of health-related quality of life: properties and applications. Ann Med 33: 328-336.

Social Insurance Institution (2003): Yearly statistics on medications. Helsinki: Social Insurance Institution.
Spry P \& Sparrow JM (2001): An evaluation of open angle glaucoma against the NSC criteria for screening viability, effectiveness and appropriateness. Available online at http://rms.nelh.nhs.uk/screening/viewResource. asp?categoryID $=1352 \& d g=107 \& u r i=h t t p \%$ 3A//libraries.nelh.nhs.uk/common/resources/ $\% 3$ Fid $\% 3 D 61002$.

Tielsch JM, Katz J, Singh K, Quigley HA, Gottsch JD, Javitt J \& Sommer A (1991): A population-based evaluation of glaucoma screening. The Baltimore Eye Survey. Am J Epidemiol 134: 1102-1110.

Tuck MW \& Crick RP (1997): The cost-effectiveness of various modes of screening for primary open angle glaucoma. Ophthal Epidemiol 4: 3-17.

Tuulonen A (2004): Is more always better? Editorial. Acta Ophthalmol Scand 82: 377 379

Tuulonen A, Airaksinen PJ, Erola E et al (2003): The Finnish evidence based guideline for glaucoma. Acta Ophthalmol Scand 81: $3-18$.

Tuulonen A, Airaksinen PJ, Montagna A \& Nieminen H (1990): Screening for glaucoma with a non-mydriatic fundus camera. Acta Ophthtalmol 68: 445-449.

Tuulonen A, Alanko H, Hyytinen P, Veijola J, Seppänen T \& Airaksinen PJ (2000): Digital imaging network in ophthalmology and microtexture analysis of the nerve fiber layer. J Glaucoma 9: 5-9.

Tuulonen A \& Sintonen H (2006): Health economics, cost-effectiveness and glaucoma care. In: Grehn F \& Stamper R (eds) Essentials in ophthalmology: glaucoma. Berlin: Springer, 123-133.

Wormald RPL \& Rauf A (1995): Glaucoma screening. J Med Screening 2: 109-114.

Received on October 4th, 2006

Accepted on March 26th, 2007.

Correspondence:

Anja Tuulonen

Department of Ophthalmology

University of Oulu

PO Box 5000

FI-90014 Oulu

Finland

Tel: +35883153299

Fax: + 3588330122

Email: anja.tuulonen@ppshp.fi 